\title{
Conhecimento, saber e poder: uma perspectiva descolonial no Ensino Médio Politécnico?
}

\author{
Knowledge, knowledge and power: a decolonial perspective \\ in Polytechnic High School?
}

\author{
Jorge Luiz Ayres Gonzaga ${ }^{1}$ \\ Gilberto Ferreira da Silva ${ }^{2}$
}

\section{RESUMO}

O presente estudo tem como objetivo analisar a reestruturação curricular realizada no Estado do Rio Grande do Sul no período do ano de 2011 a 2014, denominado de Ensino Médio Politécnico. Procura compreender em que dimensão esta reestruturação contribuiu para qualificação da educação pública. 0 referencial teórico está articulado em três concepções e em suas possíveis aproximações sendo elas a propostas elaboradas por Karl Marx explicitadas no Materialismo Histórico e Dialético, nas concepções de Modernidade e Colonialidade, na Descolonialidade do saber e do poder elaboradas por Aníbal Quijano, da Filosofia da Libertação de Enrique Dussel e nos princípios da Educação Popular concebidos por Paulo Freire. A metodologia de pesquisa utilizada é a concepção dialética da história a partir das análises do referencial teórico, dos documentos emanados pela Secretaria Estadual da Educação do Estado do Rio Grande do Sul e em resultados de avaliações externas do INEP e do ENEM ambos vinculados ao MEC e estudos de pesquisadores sobre o tema no nível de mestrado e doutorado. Os resultados apontam para qualificação desta etapa da Educação Básica. Os índices de retenção e de abandono obtiveram significativo declínio bem como as avaliações de proficiência como demonstram os gráficos no estudo.

\section{PALAVRAS-CHAVE}

Reestruturação Curricular. Ensino Médio Politécnico. Descolonialidade do Saber e do Poder. Educação Popular. Formação de Professores.

1 Doutor em Educação no PPG/Centro Universitário La Salle/Canoas/Brasil. Mestre em Reabilitação e Inclusão pelo Centro Universitário Metodista IPA. Licenciado em História pelo Centro Universitário Metodista IPA. E-mail: jl.ayresgonzaga@yahoo. com.br

2 DoutoremEducação, professor do Programa de Pós-graduaçãoemEducação e do Curso de Pedagogia da Universidade La Salle/Canoas. Pesquisador do CNPq. Líder do Grupo de Pesquisa emEducação Intercultural. Coordenador da Linha de Pesquisa Formação de Professores, teorias e práticas educativas. E-mail: gilberto.ferreira65@gmail.com 


\section{ABSTRACT}

This study aims to analyze the curricular restructuring carried out in the State of Rio Grande do Sul in the period from 2011 to 2014, called Polytechnic High School. It seeks to understand the extent to which this restructuring contributed to the qualification of public education. The theoretical framework is articulated in three conceptions and in their possible approximations, they being the proposals elaborated by Karl Marx made explicit in the Historical and Dialectical Materialism, in the conceptions of Modernity and Coloniality, in the Decoloniality of knowledge and power elaborated by Aníbal Quijano, of the Philosophy of Liberation of Enrique Dussel and the principles of Popular Education conceived by Paulo Freire. The research methodology used is the dialectical conception of history based on the analysis of the theoretical framework, the documents issued by the State Secretariat of Education of the State of Rio Grande do Sul and on the results of external evaluations by INEP and ENEM both linked to MEC and studies by researchers on the topic at the master's and doctoral level. The results point to the qualification of this stage of Basic Education. The retention and dropout rates experienced a significant decline as well as the proficiency assessments as shown in the graphs in the study.

\section{KEYWORDS}

Curricular Restructuring. Polytechnic High School. Decoloniality of Knowledge and Power. Popular Education. Teacher training. 


\section{Introdução}

As relações entre colonizador e colonizado atravessam toda a condição humana inscrita no processo de colonização a partir da "colonização e exploração" da América em um determinado momento, e da Expansão Imperialista do Capitalismo em um segundo. A pergunta central neste texto é: Como é possível outra concepção de saber e de poder não centradas e decorrentes dos objetivos coloniais europeus? A relação entre as nações colonizadoras e nações colonizadas desde a perspectiva teórica da descolonização preconizada pelo Grupo de intelectuais latino-americanos denominado Modernidade/Colonialidade, é o caminho que se aposta para fazer esta reflexão.

Nessa direção, aponta-se para a construção de possibilidades de articulação social baseadas em outras formas de concepção política, econômica, social, cultural e epistemológicas que caminhem em direção diferente da preconizada pelos paradigmas europeus, ou seja, aqueles advindos na contemporaneidade do capitalismo e suas estruturas fundantes. Neste sentido, procura-se compreender como políticas educacionaispodem ser articuladas a outras possibilidades de construção do conhecimento, por intermédio dos processos de aprendizagem, sob a égide dos conceitos de Modernidade/Colonialidade a partir de outra ética do saber e do poder fundamentado no processoColonialidade/Descoloniedade. Precisamente procuraremos questionar se existe aproximação entre os conceitos de Modernidade/Coloniedade com o processo de reestruturação curricular implementado no estado do Rio Grande do Sul nos anos compreendidos entre 2011 à 2014, e as teorias e conceitos que fundamentaram esta proposta de reorganização curricular e sua continuidade ou não como política pública de educação e se sua política pedagógica pode ou não expressar ou modelo que possibilite a mudança social. Tomaremos como proposta a análise dos conceitos de Protagonismo Juvenil, Pesquisa como Princípio Educativo e do Seminário Integrado a partir dos estudosde Pontes (2015), Araújo (2015), Maia (2015) e Alves (2014) caracterizados por serem estudos de caso e de Munsberg (2014) por ser levantamento do estado da arte.

\section{0 processo colonial como elemento fundante ao desenvolvimento do capitalismo}

Sem dúvida os estudos realizados sob a perspectiva Colonialidad e Modernidadde Aníbal Quijano $(2014,2010,2000,1992)$, (MIGNOLO, 2009, $2008,2007)$ colocam os processos denominados de Mercantilismo, as Grandes Navegações, a estruturação do Estado Nacional Absolutista, o Renascimento, o Humanismo e, por, fim, a Reforma Protestante como elementos que proporcionaram e fundamentaram as bases do Estado Moderno e embasados no modo de produção capitalista e na Modernidade como conceito chave para compreensão deste período histórico que se estende, com algumas variáveis, até nossos dias. Assim sendo, o conjunto dos processos acima evidenciados contribuíram de maneira central para constituição hegemônica na Europa Ocidental, e posteriormente no final do século XIX e início do século XX dos Estados Unidos da América, como nações em que o modo de produção capitalista se consolidou de maneira hegemônica a absoluta.

A partir desta concepção que se expressa no plano econômico, político, ideológico e, portanto, cristalizando-se em todos os aspectos culturais a visão eurocentrada de desenvolvimento, de civilização e de sociedade constituídas sob a égide da Modernidade. Isso significa afirmar que a Europa e os países que representaram o desenvolvimento do capitalismo se tornaram o paradigma do desenvolvimento e do devir social de todas as sociedades terrenas. Aliados as condições econômicas e políticas se somou a concepção religiosa apregoada pelo catolicismo que tinha e tem por finalidade levar suas doutrinas e seus dogmas como elementos constituintes de universalidade.

Não foi àtoa que o desenvolvimento do conhecimento ligado ao poder material, temporal e espiritual esteve, e está ainda hoje ligado, a instituições religiosas. Também não foi sem despropósito que o conhecimento e o poder construídos historicamente pelos povos conquistados e colonizados - não somente na América, mas, também na África e na Ásia e hoje nos conflitos no Oriente Médio $^{3}$ - estão rela-

\footnotetext{
${ }^{3} \mathrm{O}$ objetivo do texto não é discutir a questão relacionada especificamente ao conflito no Oriente Médio e as práticas denominadas de terroristas. Porém não podemos desconsideram a
} 
cionados às questões econômicas e religiosas, foram descartados como conhecimentos válidos. Neste contexto, de conquista e colonização atrelado a uma organização produtiva e social que se expressa na cultura, as sociedades conquistadas e dominadas no processo de expansão europeia foram todas elas solapadas em suas estruturas e configurações sociais centenárias e milenares.

Desta maneira, por intermédio da força da espada e da força da cruz, os povos conquistados e, emparticular, os povos americanos, foram destituídos de toda sua organização do conhecimento e, portanto, do poder. Podemos destacar a abordagem de Mignolo (2009) que nos remete a compreensão de que o conceito de Europa e posteriormente os conceitos de Colonialidad e Modernidad somente se cristalizam a partir da descoberta da América em 1492. 0 autor afirma que o Renascimento que comumente se aceita como o início da Idade Moderna e do conceito de Modernidade é o lado obscuro da Colonialidad e da Modernidad como construção política, econômica e cultural alicerçadas ideologicamente no catolicismo. Segundo o autor: "La ideadelladooscurodelRenascimiento transcendelos limites de ladistinción que comumente se estabelece entre elRenascimiento y el período moderno temprano" (MIGNOLO, 2009, p.167).

Ou seja,o Renascimento por si só não define o processo da modernidade europeia. Esta Modernidade somente se estabelece a partir da descoberta da América e do processo dual de exploração e colonização. Destacamos que não é somente no aspecto econômico que se constitui o binômio da Colonialidad e Modernidad como conceitos de consolidação da Europa e do pensamento eurocentrado. Este binômio colonial moderno está sustentado no saber, no poder e no ser. Na mesma direção, Quijano afirma que:"Com la conquista de las sociedades y las culturas que habitanlo que hoy es nombrado como América Latina, comezólaformación de una ordem mundial que culmina, 500 anõsdespués, en um poder global que articula todo el planeta" (QUIJANO, 1992, p.11).

enorme pressão expressada hegemonicamente do modo de produção capitalista em todas as manifestações humanas que vão desde a organização econômico-produtiva, política, social, cultural e religiosa. Parafraseando Marx poderíamos afirmar que todos os costumes e tradições inseridos nas culturas humanas se "dissolvem no ar" por necessidade do modo de produção capitalista.
Na constituição da Colialidad/Modernidad a partir da descoberta e exploração da América o padrão da sociedade europeia acabou por se sobrepor de maneira autoritária e irracional sobre as populações nativas do continente americano. Os diversos modos de produção, de organização social, cultural e religiosa das populações americanas foram solapados violentamente com a força da espada e a cruz. A influência da Igreja Católica se faz presente até hoje na educação brasileira e em outras nações da América Latina.Se, por um lado, a educação se fundamentou na ideologia e, sobretudo, nasconcepções e metodologias elaboradas pelo catolicismo, já o modo de produção capitalista norteou a formação tecnológica necessária ao seu modelo produtivo e a legitimação das diferenças e desigualdades de classes. Segundo Mignolo, analisando as ponderações do sociólogo aymara e ex Ministro da Cultura e Educação da Bolivia sobre o momento atual afirma que: [...] No sistema atual (neo) liberal, gestão de recursos e trabalho e gestão de distribuição social, como sabemos, são engendradas visando à acumulação de riquezas, apropriação individual de recursos naturais e exploração do trabalho (das minorias quantitativas) (MIGNOLO, 2008. p. 317).

Esta afirmação coloca em primeiro plano a relação entre a organização europeia e, posteriormenteestadunidense, como modelo hegemônico iniciado com a descoberta da América ${ }^{4}$. Neste contexto, as organizações produtivas como as guaranis, caigangues, aymaras e outras tantas foram destruídas pela lógica exploratória mercantil e capitalista. Para ilustrarmos novamente acompanhamos a afirmação de Mignolo que expressa que:

[...] A educação (na família, na escola e no treinamento avançado), a economia e a política são diferentes aspectos da organização comunal, que é chamada de ayllu em Aymara, oikos em grego, e estado em líguas europeias modernas vernáculas e imperiais [...] (MIGNOLO, 2008, p. 317-318).

\footnotetext{
${ }^{4}$ Não podemos esquecer que as riquezas exploradas da América Latina (ouro, prata, produtos agrícolas) foram determinantes no processo de acumulação de riqueza no processo de consolidação do capitalismo, bem como, o tráfico de escravos que produziam ganhos na compra e venda de seres humanos, na exploração da mão de obra e no comércio triangular.
} 
Atualmente vivemos o paradigma educacional centrado na "razão" e no "racionalismo". Este paradigma defende a absolutização do modelo racional na construção do conhecimento.Germaná(2014) quando realiza estudos a partir das concepções de Quijano, destaca a possibilidade de construção de uma epistemologia que esteja relacionada direta e umbilicalmente com a realidade das populações da América Latina. Destaca que esta realidade sempre esteve subordinada ao modelo de Colonialidad e Modernidad europeia e aos seus interesses de universalização de sua organização produtiva e societária como se esta fosse o processo teleológico da humanidade. Segundo o autor:

Em los escritos de José Carlos Mariátegui ${ }^{5}$, dada su perspectiva cognoscitiva, se encuentra uma manera de producirconoscimientos sobre la sociedade que apunte a dar cuenta de la realidade histórico-social indoamericana como uma formación social específica. Non concebia que para conocerla vida social había que aplicar um esquema teórico ya estabelecido; más bien, pensaba que era necessário encontrar los conceptos adecuados em laprópiarealidad (GERMANÁ, 2014, p.75).

Neste contexto, a exploração europeia por intermédio da colonização e constituição da Modernidade, destruiu a organização social dos povos americanos nos aspectos produtivos e culturais. Os processos de construção dos conhecimentos autóctones foram violentamente destruídos e substituídos pelo modo colonialista/capitalista/ moderno. Na perspectiva epistemológica e pedagógica podemos destacar a reflexão de Mariátegui (2011) sobre a relação entre o modelo europeu e a relação com as comunidades nativas da América. Segundo o autor peruano:

[... “ “O comunismo Inca - que não pode ser negado ou diminuído porque se desenvolveu sob o regime autocrático dos incas- pode, portanto, ser designado como comunismo agrário". Rejeitando a concepção linear e eurocêntrica da história imposta pelos vencedores, ele sustenta que a conquista colonial destruiu e desorganizou a

\footnotetext{
${ }^{5}$ A obra de José Carlos Mariátegui em que encontramos subsídios que nos faz seguir a citação de Germaná é na obra "Por um socialismo Indo-americano". Ver referências.
}

economia agrária inca, sem substituí-la por uma forma superior (MARIÁTEGUI, 2011, p. 19-20).

Esta forma de organização Inca a que Mariátegui se refere, não é somente uma organização produtiva, é também uma organização epistêmica e pedagógica. Epistêmica porque é uma maneira determinada de construção do conhecimento relacionada indelevelmente ao modo de produção e as representações simbólicas que se faz das relações sociais e pedagógicas porque se substantivam por intermédio da educação e dos processos de aprendizagem relativos à organização social e produtiva hegemônica. Essa organização no capitalismo tanto epistêmica quanto pedagógica, se expressa pelo uso instrumental da razão - inclusive pelo seu uso irracional ${ }^{6}$-, no que tange a produção e reprodução do capital.

\section{A necessidade de uma nova proposta para o Ensino Médio}

Vejamos em linhas gerais como se estrutura os processos de aprendizagem no modo de produção capitalista. No início do século XX a estruturação se deu a partir do modelo taylorista-fordista. As escolas se organizaram a partir deste modelo que está centrado na disciplina dos corpos e das mentes, na repetição dos processos de aprendizagem, na construção do conhecimento fragmentado ${ }^{7} \mathrm{e}$ nos processos de divisão social do trabalho culminando na alienação dos sujeitos. Este caminho percorrido pelo modelo hegemônico da organização produtiva e social, na atualidade se investe no modelo do capitalismo sob o paradigma da flexibilidade (HARVEY, 2013). 0 que se faz necessário para esta nova configuração produtiva é trabalhadores que dominem essa nova tecnologia, ou seja,

\footnotetext{
${ }^{6}$ Podemos citar como exemplo desta irracionalidade a produção de alimentos que não visa saciar a fome da população, mas sim, produzir a acumulação primitiva do capital. No Império Incaico a produção de alimentos era controlada pelo modelo estatal Inca e era distribuída conforme as necessidades das populações do Tahuantinsuyo.

${ }^{7} \mathrm{O}$ conhecimento fragmentado tem dois grandes objetivos. Primeiro potencializar o máximo o conhecimento em suas especificidades e particularidades articuladas as necessidades de avanços tecnológicos da produção, e segundo a finalidade de caráter ideológico em que a fragmentação social do trabalho se faz necessário para produzir processos de alienação.
} 
a tecnologia que está embutida nas máquinas. São necessário trabalhadores que resolvam "situações problemas" e não mais meros repetidores de processos estanques. Isso mostra o descompasso da organização produtiva e social dos processos arcaicos da educação.

As análises realizadas nesse estudo foram realizadas apartir dos documentos oriundos das propostas de reestruturação curricular para o Ensino Médio e as dissertações de mestrado e teses de doutorado abrangendo o período de 2012 a junho de 2018 sendo acrescentado mais um estudo posteriormente. Os documentos orientadores para reestruturação curricular foram aqueles emanados pela Secretaria da Educação, sendo eles os seguintes: a) Proposta Pedagógica para o Ensino Médio Politécnico e Educação Profissional Integrada ao Ensino Médio e, b) Regimento Referência para o Ensino Médio Politécnico. No âmbito das dissertações e teses foram copilados e analisados cinquenta e cinco(55) estudos sendo 48 dissertações e sete (7) teses de doutorado distribuídas nas seguintes categorias que emergiram a priori: "Reestruturação Curricular no Ensino Médio Politécnico", Seminário "Integrado", "Pesquisa”, ‘Protagonismo Juvenil", "Formação Docente", "Interdisciplinaridade", "Avaliação Emancipatória".

Assim sendo, as análises se constituíram nas pesquisas realizadas sob o descritor de "Reestruturação Curricular no Estado do Rio Grande do Sul no Ensino Médio Politécnico" (GONZAGA, 2018). Articulado a estas categorias que emergiram da pesquisa desenvolveu-se as análises com os conceitos das "Concepções da Educação de Marx" e nos escritos posteriores fundamentados nestas concepções, do conceito de "Descolonialidade" e, em particular, do saber e da "Educação Popular" desenvolvidas por Paulo Freire. Essas articulações desaguaram nas análises realizadas levando-se em conta a realidade brasileira e o processo histórico que se constituiu nas configurações da educação em nosso país tento na esfera teórica e conceitual bem como metodológica.

Na rede pública de educação do Estado do Rio Grande do Sul, foi proposta a reestruturação do Ensino Médio tendo início as discussões em 2011 com a comunidade escolar e a implementação em 2012. Esta etapa da Educação Básica possui um número elevado de retenção, reprovação e evasão de educandos. A organização curricular proposta tentou inverter o modelo fragmentado e disciplinar da construção do conhecimento. Na organização tradicional o currículo é composto de "disciplinas" a partir da base curricular nacional e na escola é organizado pedagogicamente a partir das disciplinas de maneira fragmentada e sem diálogo com a totalidade do currículo. Como exemplo podemos citar que os textos estudados no componente curricular de Língua Portuguesa são completamente distantes dos conhecimentos de História; os textos de Língua Estrangeira não possuem relação nenhuma com o componente curricular de Filosofia, Sociologia ou Biologia ou com os conhecimentos estudados e Artes ou Educação Física; o componente de Matemática não possui relação nenhuma com o estudo a partir do triângulo retângulo , pesos e medidas utilizados ao longo do desenvolvimento da diversas populações mundiais; o estudo de Geografia não está articulado ao estudo de química, Física ou mesmo História e, assim por diante,com todos os componentes curriculares. Ou seja, o currículo se organiza da parte pata o todo do contexto social. Este modelo epistemológico e pedagógico está ainda ancorado no modo de produção taylorista-fordista que não satisfaz mais ao modo de produção capitalista.

A proposta na rede de educação do Estado do Rio Grande do Sul teve como objetivo político a inserção das classes populares a educação que não se esgotasse somente nas necessidades prementes do capitalismo (SEDUC-RS, 2011). A organização curricular teve como ponto norteador a proposta de que os educandos pudessem acessar os conhecimentos e as técnicas que fundamentam as tecnologias atuais. Isso se estruturou na proposta de que o currículo não partisse dos conhecimentos estanques das disciplinas. A proposta era que a partir da realidade das comunidades e dos educandos se construísse um currículo significativo e que dessem respostas as questões inerentes a esta realidade vivenciada no cotidiano desses indivíduos. Nessa direção foi construído o espaço pedagógico do Seminário Integrado. 0 Seminário Integrado é o espaço em que ocorre a articulação do currículo a partir de uma demanda do educando relacionado a sua realidade vivencial. Essa demanda é elaborada como projeto de pesquisa em que os componentes curriculares gravitariam e da- 
riam as contribuições especificas de cada componente curricular e da área do conhecimento do currículo (SEDUC-RS, 2011).

Outro aspecto importante é a proposta de que o conhecimento não é construído de maneira linear e progressiva ${ }^{8}$, ou seja, não é um conjunto de conhecimentos sobrepostos uns aos outros. A construção do conhecimento deve ter por finalidade conhecer a realidade na qual estamos inseridos e possibilitar a utilização dos recursos naturais, humanos e sociais da melhor maneira possível e de maneira responsável. A seguir iremos procurar demonstrar como esta proposta de reestruturação curricular pode ser elaborada pedagogicamente.

\section{A proposta de reestruturação curricular para o Ensino Médio Politécnico}

estão inseridos. Esses conhecimentos perpassam a escola e desaguam no currículo que articula os conhecimentos elaborados nos componentes curriculares por intermédio da pesquisa no Seminário Integrado.Destacamos que se inverte nesta proposta a verticalização do conhecimento entre professor e aluno. 0 conhecimento parte da realidade do educando e sua realidade vivencial e, "é elaborado como conhecimento científico" nos componentes curriculares pelos educandos e pelos educadores. Nesta organização é fundamental a interdisciplinaridade não na escolha somente dos conhecimentos que serão elaborados, mas na integração entre os educadores e comunidadeque constroem o currículo e entre professores e educandos que constroem o conhecimento.

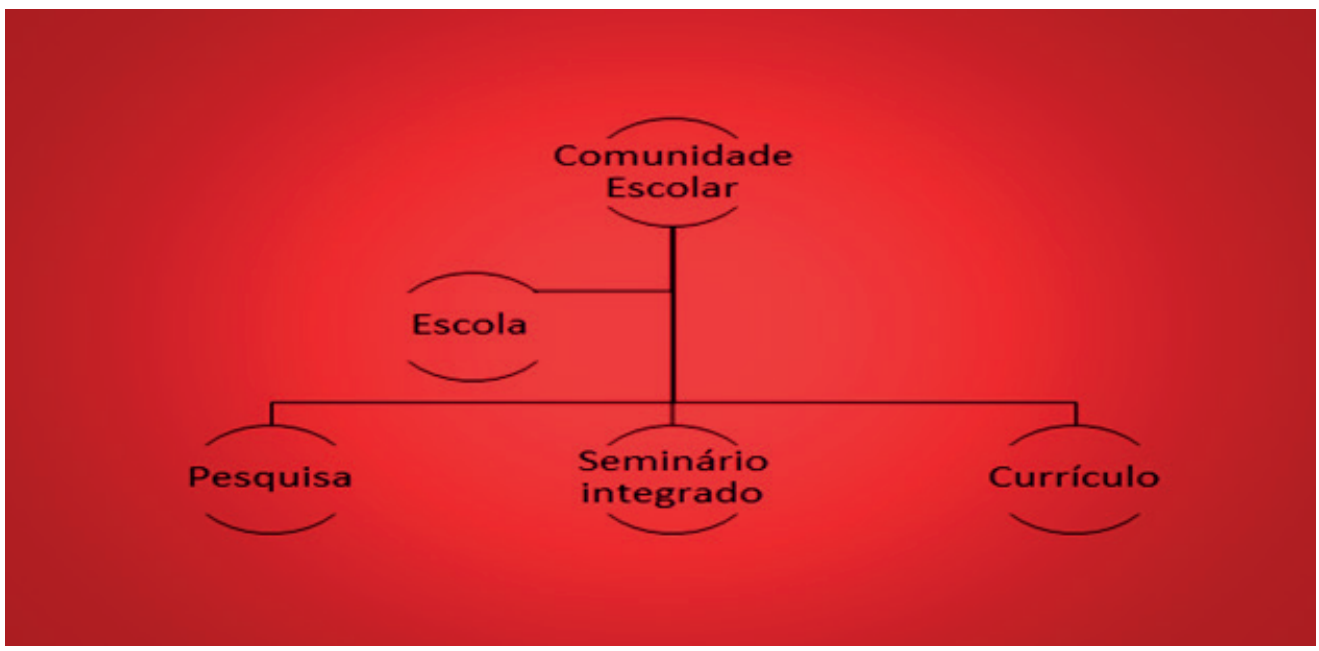

Fonte: GONZAGA, 2018.

Esta imagem mostra a organização do currículo da reestruturação do Ensino Médio Politécnico na dimensão de relação entre a escola, a comunidade escolar e o currículo. Nesta organização os conhecimentos elaborados no currículo emergem da realidade da comunidade em que os educandos

\footnotetext{
${ }^{8}$ Toma-se a ideia de progresso como se fosse um processo de ultrapassagem de etapas lineares e em uma única direção. Tomamos por exemplo a avaliação chamada apropriadamente de prova. Na prova se o educando não alcança os objetivos ele é mensurado, quantificado, qualificado e classificado para prosseguir os estudos ou ser reprovado por insuficiência. A avaliação tem por finalidade diagnosticas os entraves para serem superados e os avanços possíveis a ser percorridos.
}

A imagem a seguir demonstra a organização do currículo nas áreas do conhecimento e nos componentes curriculares. Destacamos que nesta proposta se inverte a construção verticalizada do conhecimento entre professor e aluno. 0 conhecimento parte da realidade do educando e sua realidade vivencial e "é elaborado como conhecimento científico" nos componentes curriculares pelos educandos e pelos educadores. Nesta organização é fundamental a interdisciplinaridade não na escolha somente dos conhecimentos a serem elaborados, porém, acima de tudo, na construção do conhecimento fruto da relação educando e educadores. 


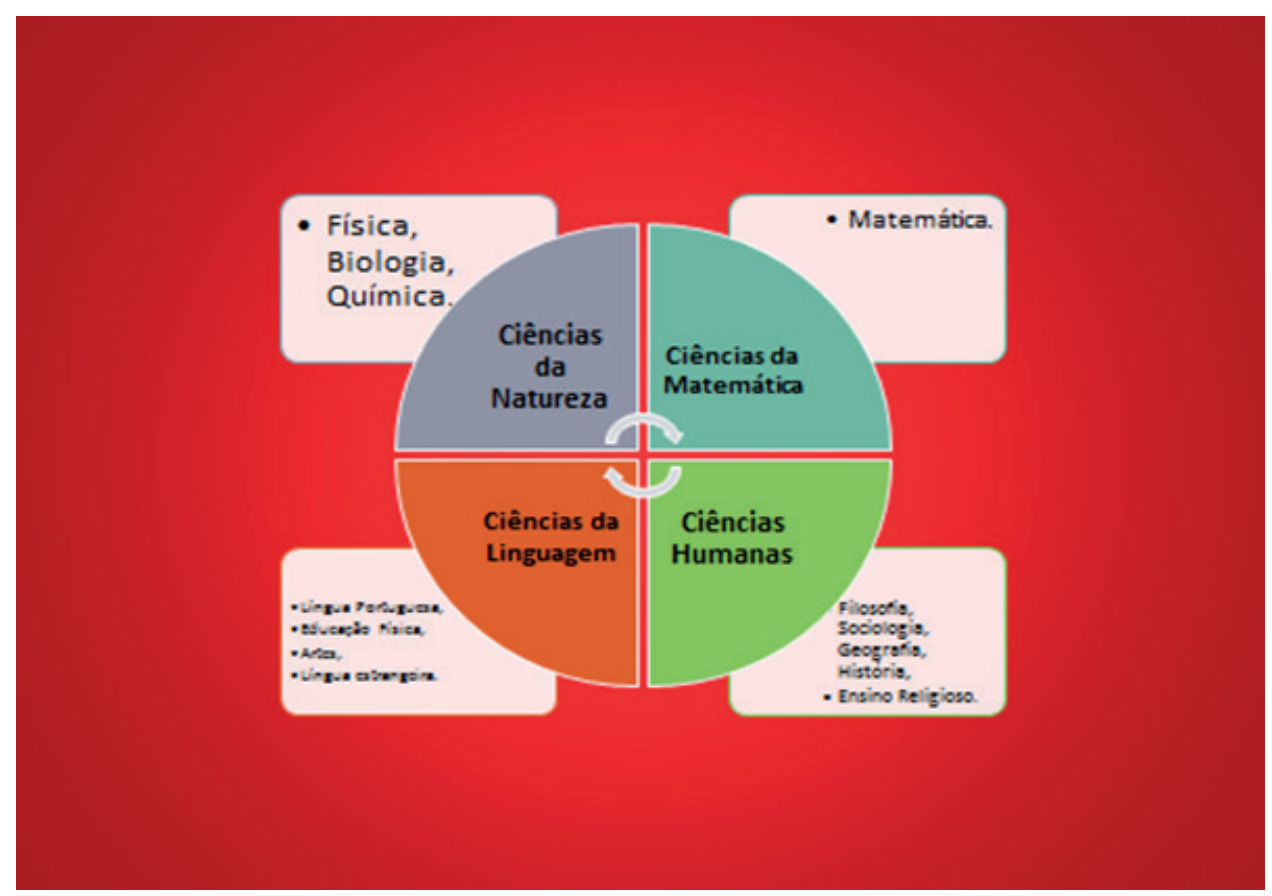

Fonte: GONZAGA, 2018.

A imagem a seguir expressa a relação das áreas do conhecimento em relação ao Seminário In- sa organização a escola e a comunidade escolar podem escolher uma temática a ser desenvolvida nas pesquisas. Essas pesquisas são elaboradas no Seminário Integrado sob a supervisão do professor coordenador.Destacamos, porém, que é nos componentes curriculares e na área que são elaborados os conhecimentos específicos de cada pesquisa.

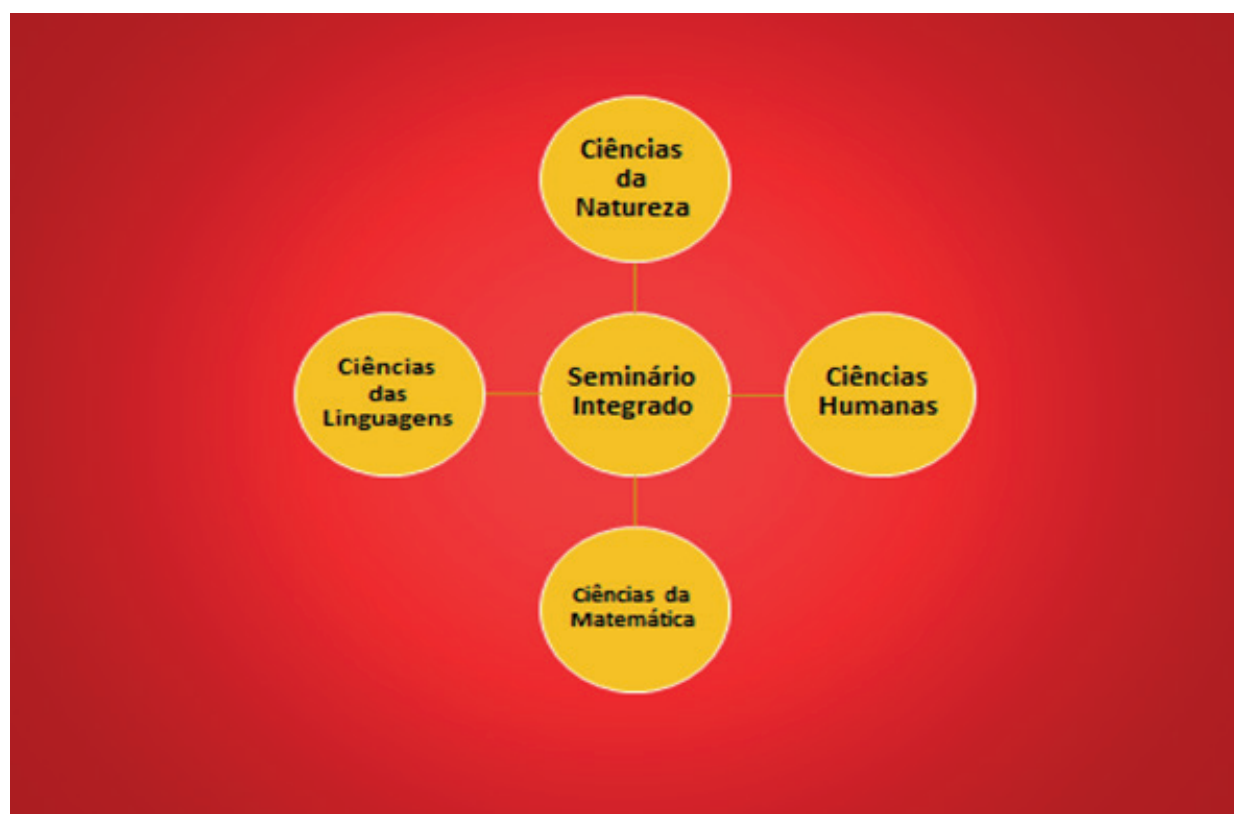

Fonte: GONZAGA, 2018. 
Esta imagem nos mostra a organização do currículo e a relação com as áreas do conhecimento, os componentes curriculares e o seminário Integrado. Destacamos que é no espaço pedagógico do Seminário Integrado que o currículo se articula como um todo orgânico no processo de aprendizagem. Este é o espaço pedagógico que se articula o conhecimento elaborado nas áreas, nos componentes curriculares por intermédio da pesquisa.

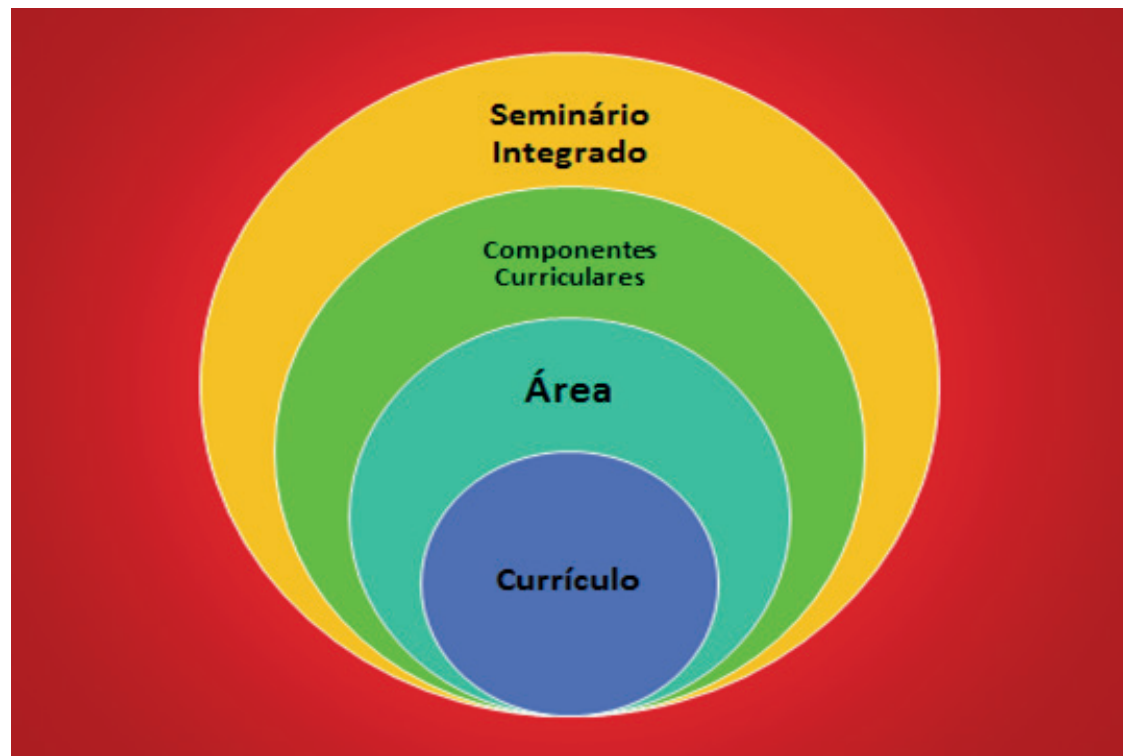

Fonte: GONZAGA, 2018

A próxima imagem mostra os conceitos que norteia a organização curricular e que lhes sustentam no campo epistemológico, metodológico e pedagógico. Ou seja, a relação entre a teoria e a prática se expressa no campo teórico e conceitual e, é evidenciada por intermédio da pesquisa; a relação entre totalidade e parte e parte e totalidade proporciona a compreensão dos fenômenos apreendidos em seu contexto e em sua finalidade; o reconhecimento dos saberes norteia a construção do conhecimento a partir da realidade dos educandos e da comunidade escolar e, é elaborado, como co-

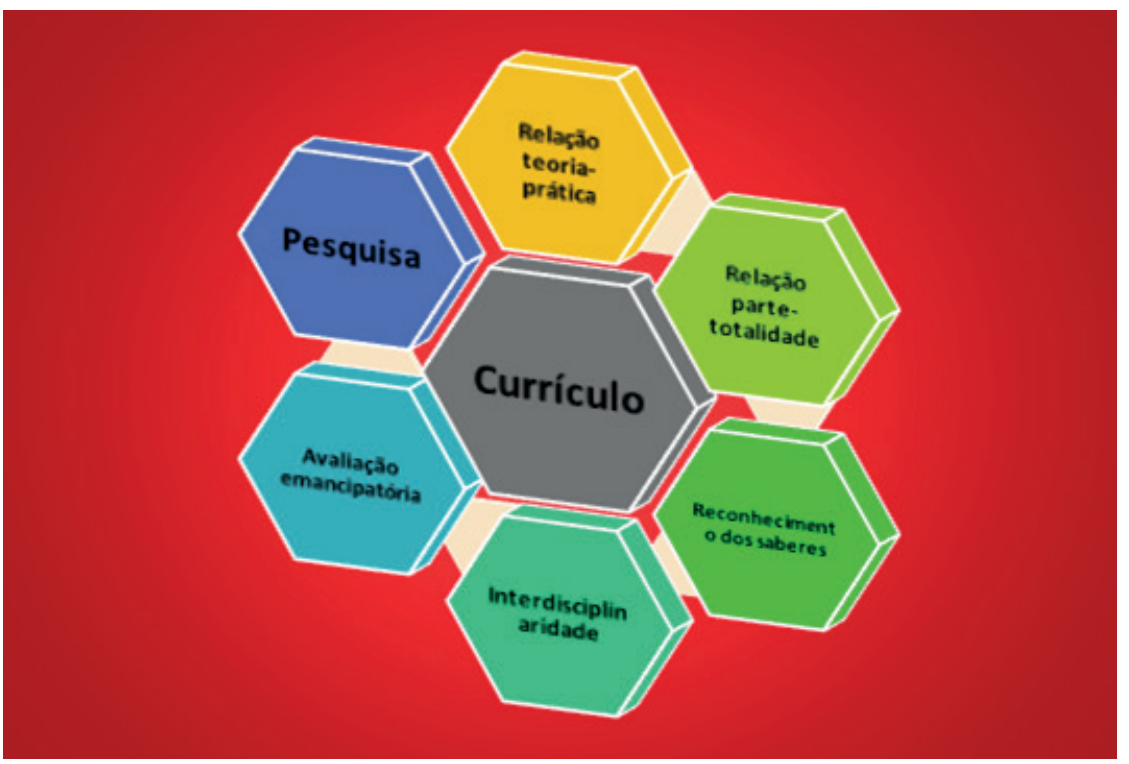

Fonte: GONZAGA 2018. 
nhecimento científico nas áreas do conhecimento e nos componentes curriculares; a interdisciplinaridade é o método de construção do conhecimento, entretanto, ela não se esgota como método e se orienta na construção ontológica do conhecimento é a avaliação emancipatória se caracteriza pelo caráter diagnóstico de compreender os entraves do processo de aprendizagem e os avanços possíveis a serem alcançados e, assim, abandona o caráter meritocrático.

Desta maneira, procuramos através das imagens elaboradas acima proporcionar uma breve síntese da proposta de reestruturação curricular do Ensino Médio Politécnico.

\section{Dados sobre a reestruturação curricular do Ensino Médio Politécnico}

Em termos concretos os dados do INEP e da secretaria da Educação do estado do Rio Grande do Sul mostram avanços significativos na diminuição dos índices de retenção, evasão e proficiência

0 gráfico (1) mostra os investimentos em educação realizados do ano de 2007 ao ano de 2016.

Fica perceptível o aumento considerável dos investimentos nos anos de 2012, 2013, 20114, 2015. Em 2016 podemos perceber o declínio nos investimentos em oposição ao aumento sistemáticos realizados nos anos anteriores.

Esses dados demonstram o crescimento dos valores investidos em educação no Estado do Rio Grande do Sul do ano de 2007 ao ano de 2016. Podemos perceber uma linha crescente de investimentos acentuando-se significativamente entre os anos de 2012 a 2015. De 2011 que tem orçamento realizado em 2010 tem-se os valores de $\mathrm{R} \$ 5.026,1$, em 2012 R\$ 5,612,1 já com orçamento do governo Tarso Genro, 2013 R \$ 6.729,8, 2014 R \$ 7.603,9 e 2016 que ainda está incluído no orçamento do governo Tarso R \$ 8.255,6. No primeiro ano do governo José Ivo Sartori a curva que era ascendente começa a declinar e o a dotação é de $\mathrm{R} \$ 8.186,3$.

Traremos agora um gráfico (2) que mostra a taxa de desempenho do Ensino Médio no Rio Grande do Sul de 2005 a 2016 nos aspectos da aprovação, retenção e abandono.

Neste gráfico podemos perceber que os índices de aprovação se mantiveram estáveis de 2005 a 2010 superiores oscilando na faixa entre $62,1 \%$

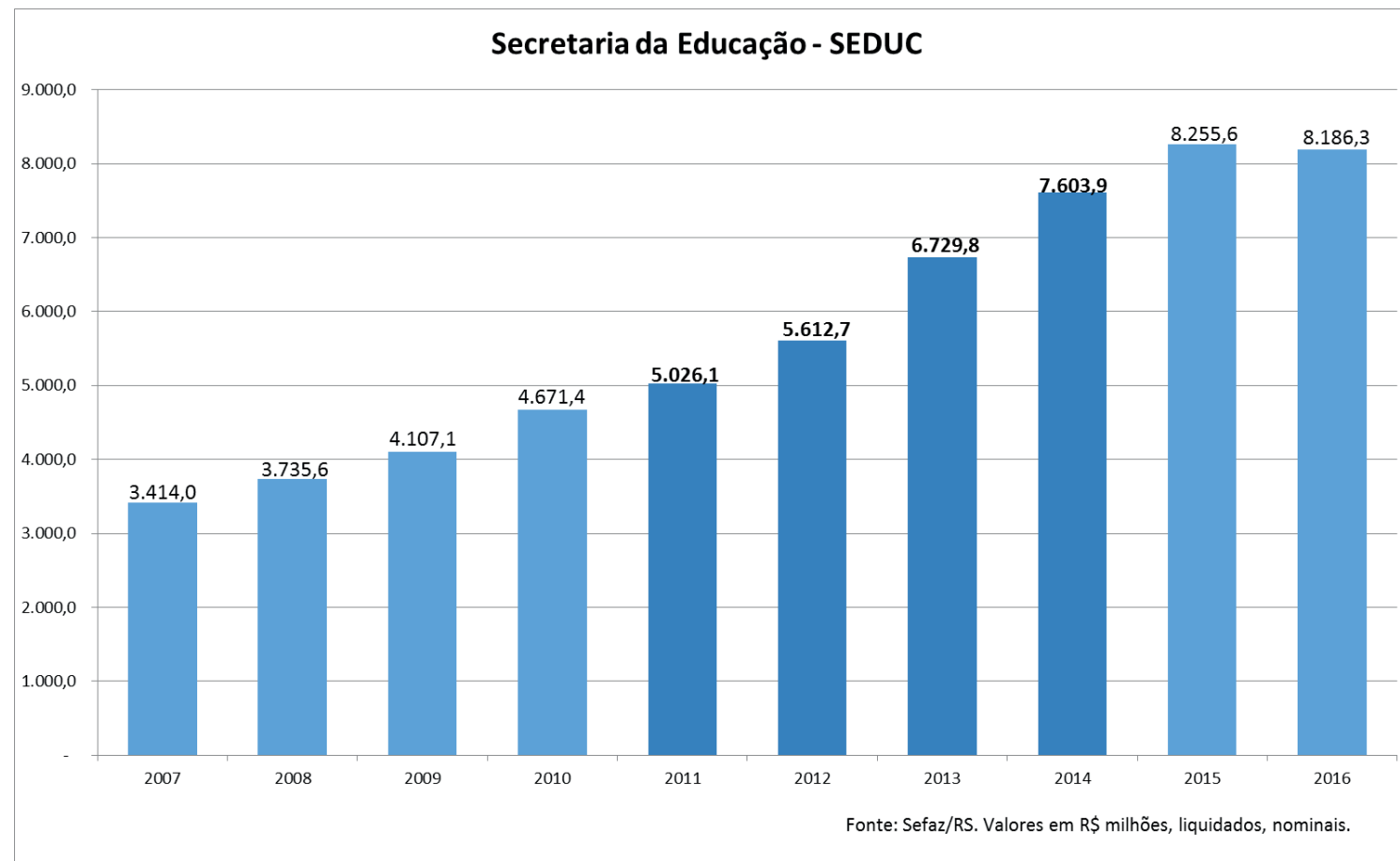

Fonte: Sefaz/RS 


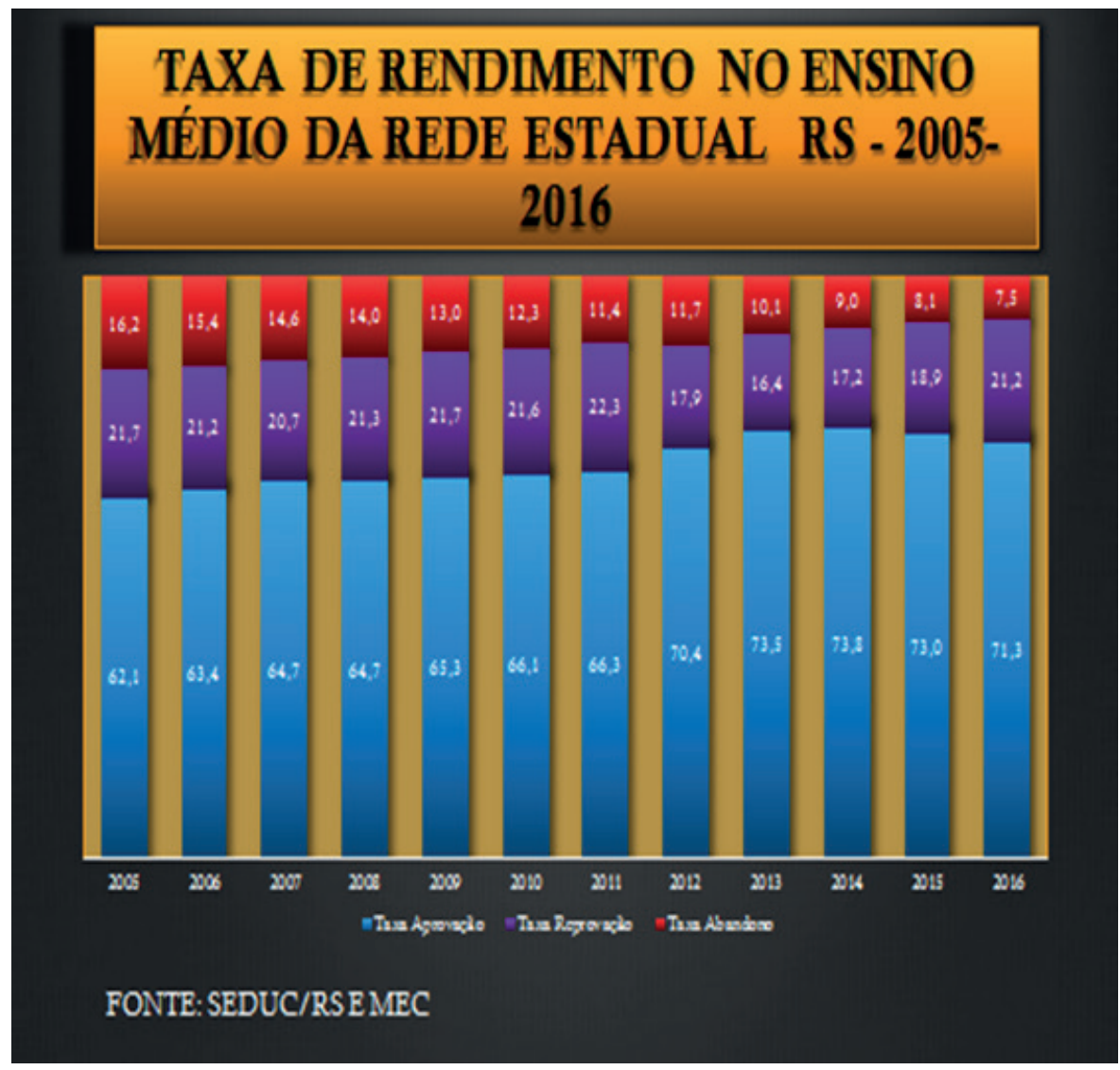

em 2005 66,1\% em 2010. No período de 2011 a 2014 ou um aumento sistemático que se iniciou com 66,3\% em 2011, 70,4\% em 2012 e 73,5 e alcançou 73,8 em 2014. Os índices a partir de 2015 com $73,0 \%$ e 2016 com $71,3 \%$ já demonstram uma linha de declínio.

Os índices de reprovação entre 2005 a 2010 oscilaram entre 21,7\% em 2005 e 21,6 em 2010, mantendo-se praticamente estáveis. Em 2011 índice foi de 22,3\% o mais elevado do período. De 2012 a 2014 no qual se formou as primeiras turmas que haviam iniciado o Ensino Médio Politécnico em 2012, os índices de reprovação declinaram significativamente, sendo de $17,9 \%$ em 2012, 16,4\% em 2013 e 17,2\% em 2014, demonstrando, assim, um declínio nos índices de reprovação. Porém, a partir de 2015 os índices começam a declinar sinalizando o abandona da proposta. Em 2015 o índice foi de 18,9 e 2016 de 21,2. Destacamos que a partir de 2015 o Ensino Médio Politécnico foi sendo abandonado em suas concepções e me- todologias. Entretanto, a organização curricular expressa no Regimento Escolar do Ensino Médio Politécnico somente pode ser alterada após três anos de vigência. Desta maneira, é possível creditar os índices dos anos de 2015 e 2016 basicamente na estruturação curricular que ainda estava sob a guarda do Regimento Escolar organizado nos princípios do Ensino Médio Politécnico.

0 último dado a ser analisado é o do abandono escolar. Do ano de 2005 a 2010 os índices de abandono oscilaram entre 16,2 em 2005 e 12,3 em 2010 e em 2011 de 11,4\%. No período que foi implementado o Ensino Médio Politécnico de 2013 até o final do governo Tarso Genro os índices de abando ficaram da seguinte maneira: no ano de 2012 11,7\%, no ano de 2013 10,1\% e no ano de 2014 o índice mais baixo de 9,0\%. Podemos destacar como havíamos sinalizado no item anterior que mesmo após o término do governo Tarso Genro o Ensino Médio Politécnico em sua organização pedagógica ainda vigorou por determinado tempo 
(tempo que a legislação permite). Mesmo assim podemos observar que o ano subsequente de 2015 teve um índice de abandono ainda menor de $8,1 \%$ e em 2016 de $7,5 \%$ o que pode demonstrar os índices como reflexos da reestruturação curricular do Ensino Médio Politécnico.
0 último gráfico (3) que iremos mostrar é aquele que demonstra o aproveitamento de nossos jovens do Ensino Médio nos anos de 2005, 2007, 2009, 2013 e 2015 apresentados pelo IDEB.

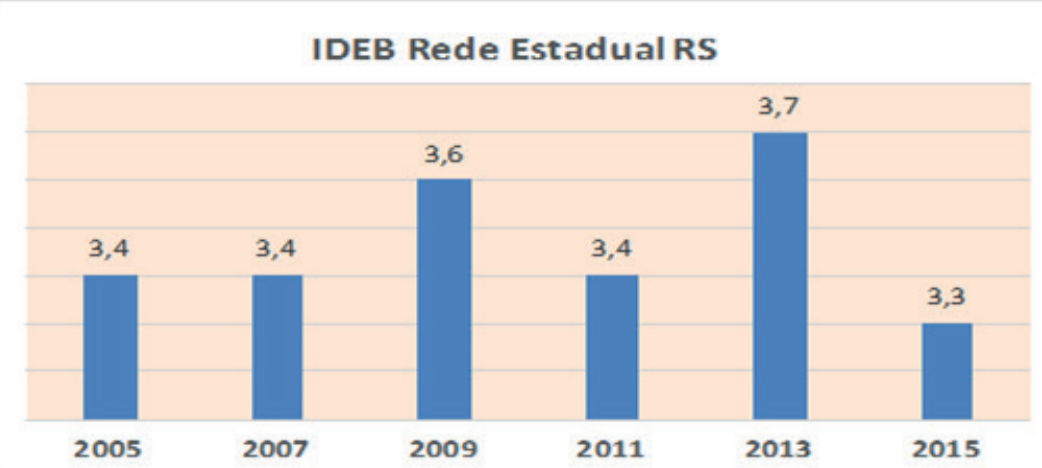

Este dado é o mais significativo em virtude de demonstrar a avaliação de proficiência dos estudantes da rede estadual. Entre os anos de 2005 e 2007 os índices se mantiveram idênticos. No ano de 2009 percebemos um aumento de 3,4 para 3,6. Em 2011 houve um decréscimo para os patamares de 2005 e 2007. Em 2013 no segundo ano de implementação do Ensino Médio Politécnico obser- vamos o maior crescimento no período analisado que se estabeleceu em 3,7. Entretanto, no primeiro ano do governo liberal de José Ivo Sartori ocorreu um decréscimo significativo atingindo o índice mais baixo entre 2005 e 2015 .

Este gráfico (4) mostra o desempenho dos educandos da rede estadual de educação do Estado do Rio Grande do Sul nos anos de 2012 e 2013 e dos outros estados da federação.

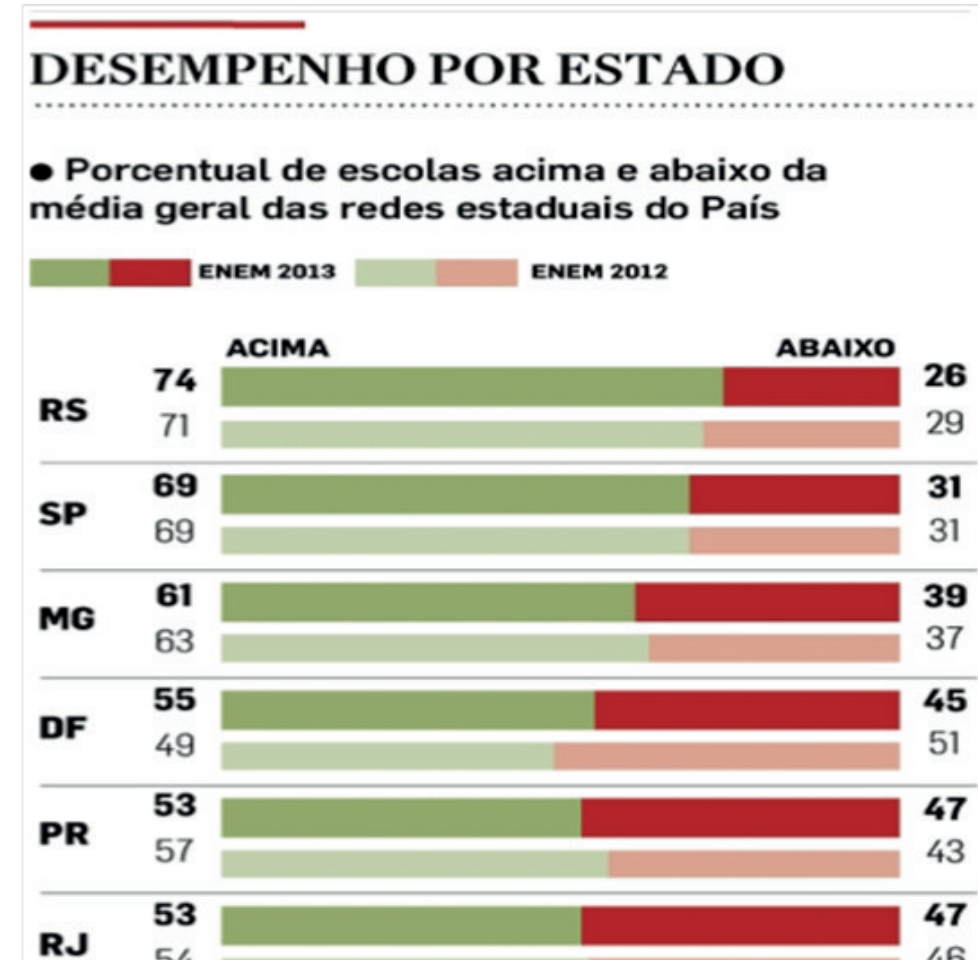




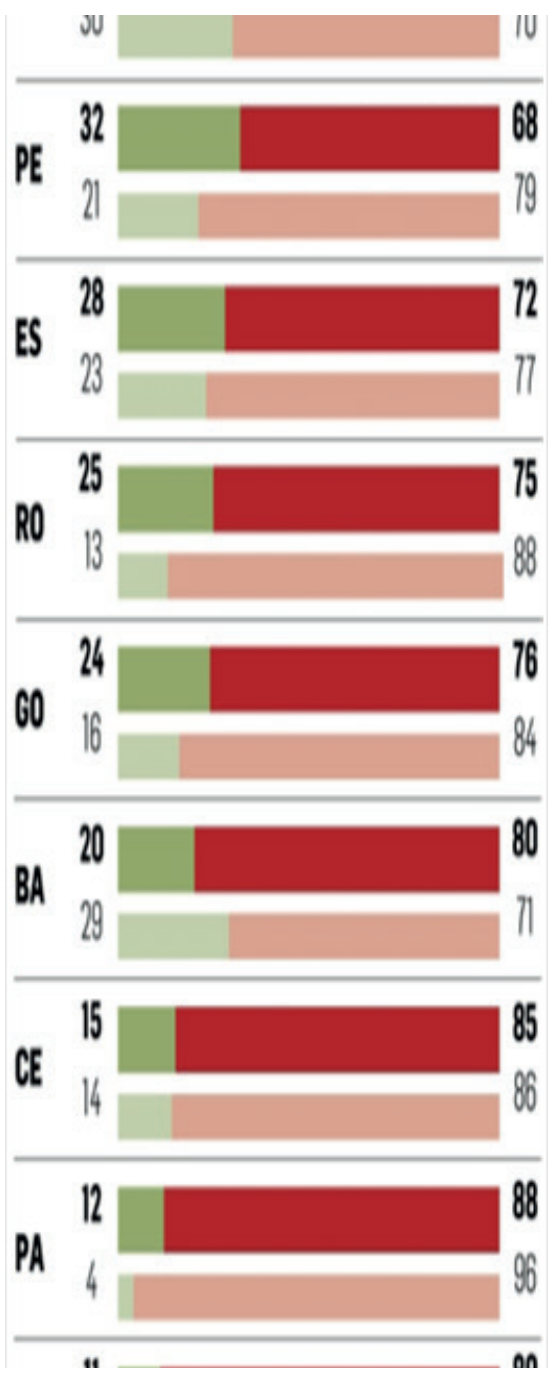

Este gráfico mostra o avanço dos educandos do Ensino Médio Politécnico entre as redes estaduais de educação. Podemos perceber um avanço no ano de 2013 em relação ao ano de 2012. Obviamente que estes dados não representam a realidade vivenciada nas escolas públicas do Rio Grande do Sul. Se muitas de nossas escolas possuem problemas estruturais de todas as ordens, também é verdade - e conhecemos isso por nossa prática docente, pela experiência maravilhosa de compartilhar com colegas de toda a rede de educação quando exercemos a função de gestão no compartilhamento de concepções e metodologias com os colegas da rede estadual de educação e como pesquisador. As realidades das escolas são enormes, e são assim em função da própria diversidade das comunidades em que as escolas estão inseridas. Nes-

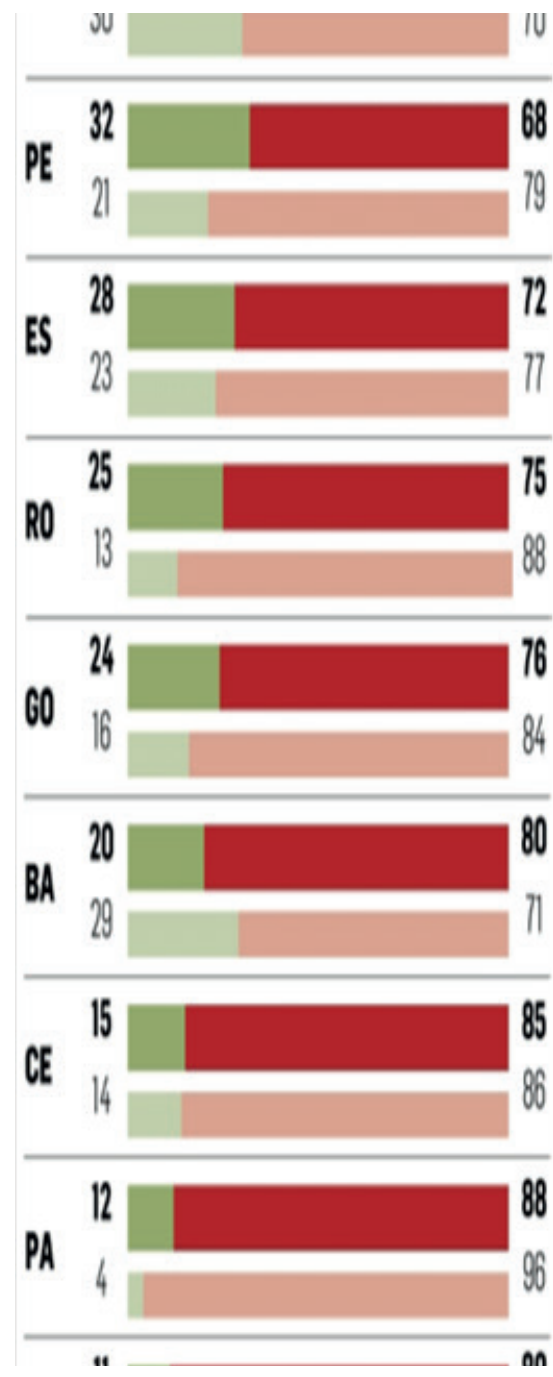

ta jornada que se iniciou em 2011 podemos perceber a "vida correndo pelos corredores das escolas". Prova disso é o número significativo de estudos realizados sobre o Ensino Médio Politécnico.

\section{Considerações provisórias}

Esse estudo tevecomo objetivo compreender se é possível construir uma proposta epistemológica e pedagógica que possibilitem a elaboração de processos de aprendizagem que não sejam instrumentos de colonialidade do saber e do poder. Temos claro que a educação formal é o espaço em que se pode reproduzir as condições sociais existentes ou que seja um local que possibilite a construção de reflexões e análises que possibilitem as transformações sociais necessária a existência e a 
qualificação da vida humana. A partir do processo de exploração e colonização da América Latina, e posteriormente na Expansão Imperialista do Capitalismo, os modelos de produção econômica, de organização social, das estruturas culturais, das simbólicas e das ideológicas foram destruídas pela concepção europeia de Colonialidade e Modernidade. As experiências milenares das populações americanas foram solapadas e descartadas em detrimento da concepção europeia de civilização, progresso e universalidade única e excludente. Desta maneira, mesmo com as imbricações do processo histórico pós colonização da América em 1492, entre colonizadores e colonizados, tais imbricações se deram pela força da espada, da religião, da economia e da cultura. Prova disso é a Colonialidade do saber e do poder. A reestruturação curricular no Ensino Médio no Estado do Rio Grande do Sul pode contribuir para a reflexão e a construção de possibilidades contra hegemônicas no campo da educação.

Neste sentido, podemos destacar que o ponto de coesão entre a reestruturação curricular elaborada para o Ensino Médio Politécnico não esteve refémdas necessidades imediatas ou duradouras do sistema capitalista, ou seja, não se configurou num instrumento de reprodução e conservação das estruturas econômicas e sociais subjugadas aos interesses da burguesia. No campo epistemológico privilegiou a construção do conhecimento por intermédio do exercício interdisciplinar da construção do conhecimento articulada a pesquisa como princípio pedagógico. Para viabilizar a concepção emancipadora do conhecimento e o princípio da pesquisa foi destinado o espaço e tempo nos Seminários Integrados. Desta maneira, podemos afirmar que o Ensino Médio Politécnico, com todas as dificuldades de gestão, comunicação e apropriação por parte dos professores, foi um movimento epistemológico e pedagógico contra hegemônico a direção única dada pelo capital a educação como totalidade que é a preparação de nossos educandos para as necessidades imediatas do mercado de trabalho capitalista. Descolonialidade significa retirar não somente as vendas epistemológicos impostas pelo capitalismo europeu conquistador e colonizador de mais de 500 anos. Descolonialidade também significa atuar de maneira concreta e articulada no interior do currículo como forma de resistências acolonialidade do saber, do poder e do ser. 


\section{Referências}

BRASIL. Instituto Nacional de Estudos e Pesquisas Educacionais Anísio Teixeira. Indicadores Educacionais Disponível em: http://portal.inep.gov.br/web/guest/indicadores-educacionais Acesso em: 10/08/2018.

BRASIL. Instituto Nacional de Estudos e Pesquisas Educacionais Anísio Teixeira. Disponível em :http://portal.inep.gov.br/ web/guest/microdados Acesso em 10/08/2018.

BRASIL. Ministério da Educação. Disponível em: http://portal. mec.gov.br/component/tags/tag/32640 Acesso em: 10/08/2018.

GONZAGA, Jorge L. A. Reestruturação curricular no Estado do Rio Grande do Sul no Ensino Médio Politécnico.

MARIÁTEGUI, José Carlos. Por um socialismo Indo-americano. 2 ed. Rio de Janeiro: Editora da Universidade Federal do rio de Janeiro, 2011.

MIGNOLO, Walter D. Desobediência Epistêmica: a opção descolonial e o significado de identidade em Política. Cadernos de Letras da UFF. № 34, p. 287-324, 2008. Disponível em http://www.uff.br/cadernosdeletrasuff/34/artigo18.pdf Acesso em 03/03/2016.

El lado más oscurodelRenascimiento. Revista Universitas humanística no. 67 enero-junio 2009. Pp:165-203. Bogotá, Colômbia issn 0120-4807. Disponível em <http://www. scielo.org.co/pdf/unih/n67/n67a09.pdf> Acesso em 04/03/2017.

El pensamientodecolonial: desprendimiento y apertura. Unmanifiesto. In: CASTRO-GÓMEZ, Santiago; GROSFOGUEL, Ramón. El giro decolonial. Reflexiones para una diversidad epistémica más alládel capitalismo global. Bogotá: SiglodelHombre Editores; Universidad Central, Instituto de EstudiosSocialesContemporáneos y PontificiaUniversidadJaveriana, Instituto Pensar, 2007. p. 25-45. Disponível em <http://www.unsa. edu.ar/histocat/hamoderna/grosfoguelcastrogomez.pdf> Acesso em 03/03/2016.

QUIJANO, Aníbal. Bienvivir entre eldesarrollo y l ades/colonialidaddel poder. Cuestiones y horizontes: de ladependencia histórico-estructural a lacolonialidad/descolonialidaddel poder. Buenos Aires: CLACSO, 2014. ISBN 978-987-722-018-6

Colonialidaddel poder, globalización y democracia. Disponível em: http://economiassolidarias.unmsm.edu. pe/?q=art-culos/colonialidad-del-poder-globalizaci-n-y-democracia. Lima: 2000. Acesso em: 23/10/2017.

Colonialidad y modernidade/racionalidade. Disponível em: https://pt.scribd.com/document/322304876/COLONIALIDAD-Y-MODERNIDAD-RACIONALIDAD-pdf. Lima: 1992 acesso em: 23/10/2017.

La crisisdel horizonte de sentido colonial/moderno/eurocentrado. Casa de Las Américas. N. 259-260 abril/septiembre/2010. p. 4-16.

QUIJANO, Aníbal; WALLERSTEIN, Immanuel. La americaniedad como concepto, o América em el moderno sistema mundial. Revista Internacional de ciências sociales. N. 134. Diciembre 1992 p. 583-592.

GERMANÁ, César. Una epistemologia otra. La contribuicción de Aníbal Quijano a lareestruturación de lasCienciasSociales de América Latina. In: QUIJANO, Aníbal (ed.). Des/colonialidad y bienvivir. Unnuevo debate en América Latina. Lima: Editorial Universitaria, 2014. p. 73-99. Disponível em <http://docs.wixstatic.com/ugd/1a6c11_1d806f9dbfc84a5697f870f7699c512e. pdf> Acesso em 13/07/2017.

RIO GRANDE DO SUL. Secretaria da Educação do Estado do Rio Grande do Sul. Censo Escolar Disponível em: http://servicos. educacao.rs.gov.br/pse/srv/estatisticas.jsp?ACAO=acao1 Acesso em $01 / 10 / 2018$.

RIO GRANDE DO SUL. SEDUC-RS. Secretaria de Estado da Educação do Rio Grande do Sul. Departamento Pedagógico -DP. Regimento Padrão do Ensino Médio Politécnico.Parecer CEED 310/2012. Disponível em: <http://www.seduc.rs.gov.br/pse/ html/ens_medio.jsp?ACAO=acao. Acesso em: 30 de fev. 2015.

RIO GRANDE DO SUL. Secretaria de Estado da Educação do Rio Grande do Sul. Departamento Pedagógico - DP. Proposta Pedagógica para o Ensino Médio Politécnico e Educação Profissional Integrada ao Ensino Médio - 2011-2014. SEDUC-RS: Porto Alegre, 2011. Disponível em: <http://www.seduc.rs.gov. br/dados/ens_med_proposta.pdf>. Acesso em: 04 mar. 2015. 